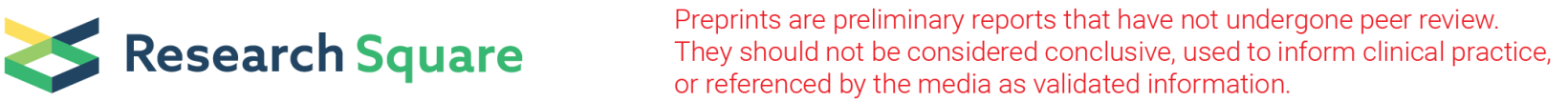 \\ Prevalence and Risk Factors for Antibiotic Utilization in Chinese Children
}

\section{Shasha Guo}

Centre for Health Management and Policy Research, School of Public Health, Cheeloo College of Medicine, Shandong University, Jinan, 250012, China

\section{Qiang Sun}

Centre for Health Management and Policy Research, School of Public Health, Cheeloo College of Medicine, Shandong University, Jinan, 250012, China

\section{Xinyang Zhao}

School of Nursing, China Medical University, Shenyang, 110100, China

\section{Liyan Shen}

Centre for Health Management and Policy Research, School of Public Health, Cheeloo College of Medicine, Shandong University, Jinan, 250012, China

\section{Xuemei Zhen ( $\nabla$ zhenxuemei@sdu.edu.cn )}

Centre for Health Management and Policy Research, School of Public Health, Cheeloo College of Medicine, Shandong University, Jinan, 250012, China https://orcid.org/0000-0002-1071-7326

\section{Research article}

Keywords: Antibiotic, Prevalence, Risk factors, Children, China

Posted Date: February 19th, 2021

DOI: https://doi.org/10.21203/rs.3.rs-244798/v1

License: (c) (i) This work is licensed under a Creative Commons Attribution 4.0 International License. Read Full License 


\section{Abstract}

Background: Antibiotic resistance poses a significant threat to public health globally. Irrational utilization of antibiotics being one of the main reasons of antibiotic resistant. Children as a special group, there's more chance of getting infected. Although most of the infection is viral in etiology, antibiotics still are the most frequently prescribed medications for children. Therefore, high use of antibiotics among children raises concern about the appropriateness of antibiotic prescribing. This systematic review aims to measuring prevalence and risk factors for antibiotic utilization in children in China.

Methods: English and Chinese databases were searched to identify relevant studies evaluating the prevalence and risk factors for antibiotic utilization in Chinese children (0-18 years), which were published between 2010 and July 2020. A Meta-analysis of prevalence was performed using random effect model. The Agency for Healthcare Research and Quality (AHRQ) and modified Jadad score was used to assess risk of bias of studies.

Results: Of 10,075 studies identified, 101 eligible studies were included. A total of 82 studies reported prevalence and 43 studies reported risk factors for antibiotic utilization in children. The overall prevalence of antibiotic utilization among outpatients and inpatients were $63.8 \%$, and $81.2 \%$, respectively. In addition, the overall prevalence of caregiver's self-medicating of antibiotics for children at home was $37.8 \%$. The high prevalence of antibiotics was associated with multiple factors, while lacking of skills and knowledge in both physicians and caregivers was the most recognized risk factor, caregivers put pressure on physicians to get antibiotics and self-medicating with antibiotics at home for children also were the main factors attributed to this issue.

Conclusion: The prevalence of antibiotic utilization in Chinese children is heavy both in hospitals and home. It is important for government to develop more effective strategies to improve the irrational use of antibiotic. In addition, there is also great need to carry out more large-scale studies of antibiotic utilization on children, especially in rural setting.

\section{Background}

Antibiotic utilization is a major driver of antibiotic resistance, which is becoming a serious public health threat, imposing a direct effect on morbidity, mortality, and financial burden[1-3]. It was reported that China was the second largest consumer of antibiotics, and up to $57 \%$ of the increase in antibiotic consumption in the hospital sector among BRICS countries (Brazil, Russia, India, China, and South Africa) was attributable to China[4]. In addition, China also has the most rapid growth rate of antibiotic resistance worldwide[5].

Antibiotics are the most widely prescribed therapy among all medications given to children[6, 7]. It was reported that the proportion of children with antibiotic prescription in the hospital settings was between $22 \%$ and $78 \%[8-13]$, at the same time, inappropriate antibiotic prescription was the most common in pediatric clinical practice[ 14,15$]$. About $50 \%$ of antibiotics were prescribed to children who were suffering 
from viral infection or non-infectious diseases, and the proportion of antibiotic prescriptions under 15 years old was three times than other ages $[16,17]$. In addition, antibiotic abuse and misuse can also result in adverse events and drug toxicity due to children's special physiological condition[18]. Children who prescribed antibiotics were more likely to have a subsequent acute bronchitis episode[19, 20]. China Antimicrobial Resistance Surveillance System (CARSS) showed that the proportions of gram-positive bacteria isolated from children and newborns was 45.5\% in 2017, which were higher than that of the adults[21]. Children may have little or even no benefit from antibiotics[22], therefore, promotion of rational use of antibiotics and reduction in antibiotic resistance in children has become an urgent problem[23, 24]. To combat this problem, the Chinese government has launched a National Antibiotic Stewardship Program (NASP), which limits the proportion of outpatient antibiotic prescriptions and inpatient antibiotic prescriptions in Children's hospitals to $25 \%$ and $60 \%$, respectively[25]. Hierarchical management was carried out for the clinical use of antibacterial drugs, which includes three levels: unrestricted use, restricted use and special use, according to safety, effect, drug resistance, and price[26]. National action plan combating antimicrobial resistance proposed to carry out health education on the rational use of antibiotics in primary and secondary schools[27].

Recently, the number of studies on the prevalence of antibiotic utilization in Chinese children has increased greatly, while sparse studies explored risk factors. Assessment of risk factors for antibiotic utilization in children may lead to a better understanding of the prevalence rates of antibiotics utilization and therefore leading to a more effective preventive strategy. In addition, most of the relevant studies were published in Chinese, with only a few in English language, which caused a lack of awareness of antibiotic utilization in China worldwide. There has not been an in-depth, up-to-date, and comparative analysis of the contemporary literature reporting the prevalence and risk factors for antibiotic utilization in Chinese children. In this study, we aimed to summarize the proportion of antibiotic usage among outpatients, inpatients, and self-medication, and investigate the major risk factors for antibiotic utilization in Chinese children.

\section{Methods}

This systematic review and meta-analysis was conducted in accordance with the Preferred Reporting Items for Systematic Reviews and Meta-Analyses (PRISMA) reporting guideline[28]. The protocol was registered with PROSPERO (CRD42020200172).(Table S1 in Appendix A)

\section{Search Strategy}

We searched three Chinese databases including China National Knowledge Infrastructure (CNKI), Chongqing VIP, and Wanfang Data, and three English databases including PubMed, Web of Science, and Embase between January 1, 2010 and July 10, 2020. Search terms were a combination of antibiotic, children, China, and prevalence (or risk factor). Then, references lists of the included studies were 
screened to complement our database searches. The detailed search strategies were presented in Table S2 Appendix B.

\section{Inclusion And Exclusion Criteria}

Inclusion criteria were: (1) studies published in English or Chinese language; (2) publication date was between January 1, 2010 and July 10, 2020; (3) original studies using any study designs, such as observational studies (cohort, case-control, cross-sectional) or randomized studies; (4) reports on children ( $\leq 18$ years old); (5) reports in China; (6) reports on prevalence rates or risk factors for antibiotic utilization. In order to update the analysis reflecting current patterns and practice guidelines, we excluded studies published before 2010. Children with special diseases (e.g. cancer, leukemia) were excluded as well. For randomized studies, we only included data in control group. Two reviewers (XY and GS) independently estimated the titles and abstracts of the retrieved studies using the above eligibility criteria, then, full texts were examined. Any discrepancies were resolved by the third reviewer (XM).

\section{Data Extraction}

A pre-designed standardized extraction form was used to record the characteristics of each study including first author, publication year, study period, study design, geographical regions, study setting (rural or urban), hospital levels, sample size (number of children), age, number of children with antibiotics, number of children with one antibiotic, number of children with antibiotic combination, and risk factors for antibiotic utilization.

\section{Statistical analysis}

For statistical analysis, STATA version 15.0 was employed. We assessed heterogeneity of prevalence estimates using $R$ index, which was categorized as low (0-25\%), moderate (26-50\%), and high (above $50 \%$ )[29].A random-effect meta-analysis was used to calculate the overall pooled prevalence of antibiotic utilization in children with $95 \%$ confidence interval $(C l)$ due to high heterogeneity. Subgroup analyses for prevalence were performed with respect to study location (outpatient, inpatient, and self-medication at home), geographical region (eastern, central, and western), setting (urban and rural area), hospital levels (level 1, 2, 3), quantity of antibiotic use (alone or in combination).

\section{Study Quality Assessment}

We assessed the included study quality using the Agency for Healthcare Research and Quality (AHRQ) for observational studies[30]. We considered 11-item checklist for quality assessment, including source of investigation, inclusion and exclusion criteria, time period, consecutive of subjects, objectivity of indicators, reproducibility of indicators, reason for subject exclusions, confounding controlled, missing 
data handled, response rate and completeness of data collection, and results of follow-up. "No" or "Unclear" was scored " 0 ", and "Yes" was scored " 1 ". We considered studies that $\leq 3$ scores as low quality, 4-7 scores as moderate quality, $\geq 8$ scores as high quality. For randomized studies, we used modified Jadad score with classification criteria of high quality (6-7 scores), moderate quality (4-5 scores), and low quality $(\leq 3)$, which included the generation of random sequences, randomization, blinding, followup. "No" was scored "0", "unclear" was scored "1", and "Yes" was scored "2" [31].

\section{Results}

\section{Study selection}

A total of 9,973 records were retrieved in the initial literature search, and additional 102 studies were identified through manual reference screens. After removing 1,395 duplicates, 8,680 studies were retrieved. Titles and abstracts screening resulting in 603 records for full-text evaluation. Finally, 101 records were included. (Fig. 1)

\section{Study Characteristics And Quality}

Of the 101 eligible studies included in our review, 82 studies reported the prevalence of antibiotic utilization of children, including 34 studies on outpatient[32-65], 43 studies on inpatient[66-108], and one study on both outpatient and inpatient[109]. Moreover, four studies reported the prevalence of selfmedication antibiotic utilization at home[110-113]. The majority of the studies were retrospective observational studies $(n=76)$, were published after 2011 year $(n=68)$, and were conducted in urban area $(n=75)$, and collected data from the Level 3 hospital $(n=50)$. The study data were obtained from 22 provinces in mainland China, with the largest number of studies from Guangdong province $(n=15)$, followed by Guangxi province $(n=9)$, and Jiangsu province $(n=7)$. A total of 50 studies collected data from the eastern economic zone, 19 studies from the western economic zone, 10 studies from the central economic zone, and three studies reported data from nationwide. In addition, 43 studies reported the risk factors for antibiotic utilization[20, 32, 33, 39, 42, 43, 49, 50, 55, 57, 64, 66, 68, 75, 77, 83-85, 91, 92, 99, 110-131], of which, five studies focused on children, 20 studies focused on physicians, 31 studies reported from caregivers, 11 studies reported from retail pharmacies, and one study reported from hospital.(Table S3, Table S4,Table S5,Table S6 in Appendix C).

Regarding the quality of included studies, for observational studies, 37 were with high quality and 58 were with moderate quality (Table S7 in Appendix D). For randomized studies, 2 were with high quality, 4 were with moderate quality. (Table S8 in Appendix D).

\section{Prevalence Of Antibiotic Utilization In Chinese Children}


The overall prevalence of antibiotic utilization among outpatients and inpatients were $63.8 \%(95 \% \mathrm{Cl}$. $55.1-72.4 \%, P=99.9 \%, P<0.0001$ ) (Fig. 2), and 81.2\% (95\% Cl. $77.2-85.3 \%, P=99.7 \%, P<0.0001$ ) (Fig. 3), respectively. In addition, the overall prevalence of caregiver's self-medicating of antibiotics for children at home was $37.8 \%(95 \%$ Cl. $7.9-67.6 \%, P=99.8 \%, P<0.0001)$ (Fig. 4).

In the subgroup analyses, the prevalence of combined use of antibiotic was $30.7 \%$ among outpatients, and $38.6 \%$ among inpatients. The prevalence of antibiotic utilization in eastern, central, and western economic zone were $59.8 \%, 80.0 \%, 70.0 \%$, respectively, for outpatients, and $80.9 \%, 78.7 \%, 80.4 \%$, respectively, for inpatients. A higher prevalence antibiotic utilization was found in urban, with $64.1 \%$ and $81.7 \%$ for outpatients and inpatients respectively. In addition, prevalence of antibiotic utilization in level 1 , 2,3 hospital were $66.4 \%, 59.1 \% 64.0 \%$, respectively, among outpatients, and $85.5 \%$ in level 2 hospital, $79.6 \%$ in level 3 hospital among inpatients. (Table 1, Table 2). 
Table 1

The prevalence of outpatient antibiotic utilization by antibiotic combination situation, economic zone, study setting, and hospital level.

\begin{tabular}{|c|c|c|c|c|}
\hline & $\begin{array}{l}\text { No. of studies } \\
(\mathrm{N})\end{array}$ & $\mathrm{n} / \mathrm{N}$ & $\begin{array}{l}\text { Percentage (95\% Cl) } \\
(\%)\end{array}$ & P-value \\
\hline \multicolumn{5}{|c|}{ Antibiotic combination situation (23) } \\
\hline Single use of antibiotic & 23 & $27736 / 36751$ & $69.3(58.2-80.3)$ & $\begin{array}{l}P< \\
0.0001\end{array}$ \\
\hline $\begin{array}{l}\text { Combined use of } \\
\text { antibiotic }\end{array}$ & 23 & $9015 / 36751$ & $30.7(19.7-41.8)$ & $\begin{array}{l}P< \\
0.0001\end{array}$ \\
\hline \multicolumn{5}{|l|}{ Economic zone (34) } \\
\hline Eastern & 24 & $68961 / 118022$ & $59.8(49.3-70.2)$ & $\begin{array}{l}P< \\
0.0001\end{array}$ \\
\hline Central & 4 & $4363 / 5244$ & $80.0(67.2-92.8)$ & $\begin{array}{l}P< \\
0.0001\end{array}$ \\
\hline Western & 7 & $5371 / 8540$ & $70.0(56.1-83.9)$ & $\begin{array}{l}P< \\
0.0001\end{array}$ \\
\hline \multicolumn{5}{|l|}{ Study setting (34) } \\
\hline Urban & 29 & $68961 / 118022$ & $64.1(54.4-73.8)$ & $\begin{array}{l}P< \\
0.0001\end{array}$ \\
\hline Rural & 6 & $15489 / 30429$ & $63.1(55.3-71.1)$ & $\begin{array}{l}P< \\
0.0001\end{array}$ \\
\hline \multicolumn{5}{|l|}{ Hospital level (34) } \\
\hline Level 3 & 18 & $61551 / 103670$ & $64.0(54.9-73.0)$ & $\begin{array}{l}P< \\
0.0001\end{array}$ \\
\hline Level 2 & 8 & $9086 / 21118$ & $59.1(33.6-84.5)$ & $\begin{array}{l}P< \\
0.0001\end{array}$ \\
\hline Level 1 & 9 & $13813 / 23663$ & $66.4(47.2-85.5)$ & $\begin{array}{l}\mathrm{P}< \\
0.0001\end{array}$ \\
\hline
\end{tabular}


Table 2

The prevalence of inpatient antibiotic utilization by antibiotic combination situation, economic zone, study setting, and hospital level.

\begin{tabular}{|c|c|c|c|c|}
\hline & $\begin{array}{l}\text { No. of studies } \\
(\mathrm{N})\end{array}$ & $\mathrm{n} / \mathrm{N}$ & $\begin{array}{l}\text { Percentage (95\% Cl) } \\
(\%)\end{array}$ & P-value \\
\hline \multicolumn{5}{|c|}{ Antibiotic combination situation (34) } \\
\hline Single use of antibiotic & 34 & $16230 / 26399$ & $61.5(53.9-69.2)$ & $\begin{array}{l}P< \\
0.0001\end{array}$ \\
\hline $\begin{array}{l}\text { Combined use of } \\
\text { antibiotic }\end{array}$ & 34 & $10169 / 26399$ & $38.6(31.0-46.2)$ & $\begin{array}{l}P< \\
0.0001\end{array}$ \\
\hline \multicolumn{5}{|l|}{ Economic zone (43) } \\
\hline Eastern & 26 & $30201 / 36977$ & $80.9(77.2-84.6)$ & $\begin{array}{l}P< \\
0.0001\end{array}$ \\
\hline Central & 9 & $17880 / 22341$ & $78.7(71.6-85.9)$ & $\begin{array}{l}\mathrm{P}< \\
0.0001\end{array}$ \\
\hline Western & 16 & $25156 / 34658$ & $80.4(71.1-89.7)$ & $\begin{array}{l}P< \\
0.0001\end{array}$ \\
\hline \multicolumn{5}{|l|}{ Study setting (43) } \\
\hline Urban & 43 & $46584 / 60478$ & $81.7(77.4-85.9)$ & $\begin{array}{l}P< \\
0.0001\end{array}$ \\
\hline Rural & 2 & $219 / 296$ & $76.3(77.2-85.3)$ & $\begin{array}{l}P< \\
0.0001\end{array}$ \\
\hline \multicolumn{5}{|l|}{ Hospital level (43) } \\
\hline Level 3 & 33 & $42233 / 55692$ & $79.6(74.6-84.6)$ & $\begin{array}{l}P< \\
0.0001\end{array}$ \\
\hline Level 2 & 13 & $4527 / 5039$ & $85.5(81.6-89.5)$ & $\begin{array}{l}P< \\
0.0001\end{array}$ \\
\hline Level 1 & 1 & $43 / 45$ & $95.6(-)$ & - \\
\hline
\end{tabular}

\section{Risk Factors Of Antibiotic Utilization In Chinese Children}

We explored the risk factors of antibiotic utilization in Chinese children using qualitative analysis from five aspects and 12 items (Table 3 ). The presentation of factors here is grouped into those at children level (e.g. distribution of disease, lack of skills and knowledge), and physician level (e.g. lack of skills and knowledge, pressure from patient, physician-patient relationship, economic incentive and profit from prescribing medicine, lack of pathogen detection or low pathogen detection rate), and caregiver level (e.g. 
lack of skills and knowledge, put pressure on physician to get antibiotics, behavior of self-medicating with antibiotics at home for children) and retail pharmacies level (e.g. sale antibiotics without prescription) and hospital level (e.g. ward capacity). 
Table 3

Risk factors of antibiotic utilization in children in China.

Risk factors

No. of

studies

$(\mathrm{N}=43)$

Children distribution of

disease

The biological systems and organs of children are not

$3(7.0 \%)$

well-developed, especially those of younger children,

which make children more vulnerable.

Children with upper respiratory tract infections (URTIs)

are among the highest receivers of antibiotics.

lack of skills Middle school students still have problems in

and

medication adherence, the management of expired

$1(2.3 \%)$

knowledge

drugs and the antibiotics cognition.

Physicians

lack of skills

Physicians consider antibiotics to be anti-

20

and

inflammatory drugs is a common misconception.

knowledge

Doctors might overprescribe antibiotics due to lack of

$(46.5 \%)$

knowledge of its rational use.

Gaps between reported knowledge and actual practice

within antibiotic prescribing are commonly

encountered.

pressure from

patient

physician-

patient

relationship

economic

incentive and

profit from

prescribing

medicine

lack of

pathogen

detection or

low pathogen

detection rate
Majority of the village doctors would prescribe

antibiotics if their patients stick to getting them.

Ineffective communication between patients and

physicians may lead to the unnecessary prescription

of antibiotics.

Retention of patients would increase physicians' consultation fees.

Doctors are able to make a profit from individual drug

prescriptions, including antibiotics, and this may stimulate over-prescribing of antibiotics.

Uncertainty in the etiological diagnosis is reported as

one of the main causes of fear when prescribing in

primary care settings.

The doctor paid little attention to microbiological examination.

Caregivers lack of skills

and

knowledge
Parents have considerable misunderstandings that may contribute to inappropriate antibiotic use.

Most of parents believe that taking antibiotics in advance could protect children from common diseases.

Parents' high expectations of quick relief of symptoms

$14(32.6 \%)$

put pressure

on physician

and recovery of their children would impose further

to get pressure on doctors to prescribe antibiotic in order to

antibiotics

make treatments more immediately effective. 


\begin{tabular}{|c|c|c|c|}
\hline & Risk factors & & $\begin{array}{l}\text { No. of } \\
\text { studies } \\
(\mathrm{N}=43)\end{array}$ \\
\hline & $\begin{array}{l}\text { self- } \\
\text { medicating } \\
\text { with } \\
\text { antibiotics at } \\
\text { home for } \\
\text { children }\end{array}$ & $\begin{array}{l}\text { Most of the parents would use lower dose of } \\
\text { antibiotics than required by the instruction with } \\
\text { consideration of safety, and some parents would } \\
\text { choose a higher dose. }\end{array}$ & $14(32.6 \%)$ \\
\hline $\begin{array}{l}\text { Retail } \\
\text { pharmacies }\end{array}$ & $\begin{array}{l}\text { sale } \\
\text { antibiotics } \\
\text { without } \\
\text { prescription }\end{array}$ & $\begin{array}{l}\text { Although antibiotics sales in retail pharmacies are not } \\
\text { within the jurisdiction of government regulation, retail } \\
\text { pharmacy is still the main channel for parents to } \\
\text { purchase antibiotics. }\end{array}$ & $11(25.6 \%)$ \\
\hline Hospitals & ward capacity & $\begin{array}{l}\text { Newborn units with more than } 100 \text { beds have the } \\
\text { highest rate of antibiotic use, compared to units with } \\
50 \text { or fewer beds, and those with } 51-100 \text { beds. }\end{array}$ & $1(2.3 \%)$ \\
\hline
\end{tabular}

Distribution of disease in children has been regarded as a risk factor influencing antibiotic utilization by $7.0 \%(3 / 43)$ of studies. A study indicated that the reasons that lead physicians prescribe antibiotics were mainly clinical determinants such as severity of symptoms, immediate clinical issue[129]. Another survey on pediatric outpatient prescription found that respiratory infection was one of the diseases with the highest frequency, the most dosage of antibiotic utilization[86]. In addition, children lacking of skills and knowledge about antibiotics also influences antibiotic utilization. Although children knew that antibiotics were not antiviral drugs, they were less able to identify specific antibiotics[121].

A total of $46.5 \%(20 / 43)$ of studies suggested that physicians lacking of skills and knowledge was an important factor influencing antibiotic utilization of children. It was indicated that nearly $30 \%$ of pediatricians considered antibiotics to be anti-inflammatories[42], and some village doctors confused to select appropriate antibiotics for children[120]. Some studies explored that pressure from patient had an effect on antibiotic prescriptions. About $70 \%$ of the village doctors complied with the primary caregivers' request even when they felt the antibiotics were unnecessary[120]. Physician-patient relationship was mentioned by $4.7 \%(2 / 43)$ of studies. Physicians wariness of medical disputes by dissatisfied patients might induce them to order unnecessary investigations and overprescribe antibiotics[77]. Economic incentives and profits from prescription also lead physicians to prescribe antibiotics. A study reported that inter-hospital competition was a driver of inappropriate prescribing, if patients did not have antibiotics they want, they will choose other hospital to purchase, leading to suffer financially[128]. A total of $18.6 \%(8 / 43)$ of studies reported that lacking of pathogen detection or low pathogen detection rate was also a risk factor. Through meta-analysis, we found that the overall pathogen detection rate among inpatients was $44.7 \%(95 \% \mathrm{Cl}$ : 29.7-59.7\%, $P=99.7 \%, P<0.0001)$, but there was no study on outpatients. (Fig. S1 in Appendix E).

A total of $67.4 \%(29 / 43)$ of studies reported that lacking of skills and knowledge from caregivers influences antibiotic utilization for children. Almost $66.3 \%$ of respondents mistakenly believed that 
antibiotics and anti-inflammatory drugs are the same drugs, $68.8 \%$ of respondents believed that antibiotics can cure infections caused by virus, $51.5 \%$ of respondents believed that antibiotics can be used to treat common cold, $69.9 \%$ of respondents believed that antibiotics can be used to treat pharyngitis or nonsuppurative tonsillitis, $37.9 \%$ of respondents didn't know antibiotics should only be obtained with a doctor's prescription, and $46.6 \%$ of respondents didn't know inappropriate use of antibiotics can reduce the effectiveness of antibiotics (Table S9 in Appendix E). 32.6\% (14/43) of studies reported put pressure on physician to get antibiotics was one of the risk factors influencing antibiotic utilization for children. A study reported that about half of the caregivers had requested antibiotics directly from physicians[117]. A total of $32.6 \%$ (14/43) of studies reported self-medicating with antibiotics at home for children was a risk factor of antibiotic utilization. A study reported that about $69.2 \%$ of caregivers would self-medication for children before visiting a doctor, in addition, to improve the effectiveness of treatment, they would increase the dosage arbitrarily[118].

For retail pharmacies, selling antibiotics without prescription has been regarded as a risk factor of antibiotic utilization for children. It was reported that individuals in most rural areas continue to have easy access to antibiotics[125]. The rate of antibiotic use was also associated with bed capacity, newborn units with more than 100 beds had the highest rate of antibiotic use, compared to units with 50 or fewer beds, and those with 51-100 beds[124].

\section{Discussion}

The prevalence of antibiotic utilization in Chinese children was high. The overall prevalence of antibiotic utilization among outpatients and inpatients was $63.8 \%$ and $81.2 \%$, respectively, and caregivers' selfmedicating with antibiotics for children at home was $37.8 \%$.

Two literature reviews reported a prevalence of $89 \%$ or $91.3 \%$ for antibiotic utilization in Chinese children, which was higher than that in our study $[108,132]$. However, our results were still much higher than the standard values of $25 \%$ for outpatient and $60 \%$ for inpatient with antibiotic prescriptions for children issued in an antimicrobial stewardship policy by Chinese government[133]. In addition, the prevalence of antibiotic utilization for children in China was higher than that in the USA (17\%-29\%)[134]. According to the ARPEC (Asia-Pacific Economic Cooperation) report, the prevalence of antibiotic utilization from 226 hospitals in 41 countries was $36.7 \%[12]$. The overall prevalence of caregiver's self-medicating of antibiotics for children at home was $37.8 \%$, which was similar to the Chang et.al's finding(37.67\%)[122], but lower than that in India (69.4\%)[135].

Children are more susceptible to infection due to their unique peculiarities of body size, surface area, drug metabolism, and excretion, which may be associated with high antibiotic prevalence. However, acute upper respiratory infections (AURIs) are the most common condition associated with the excessive use of antibiotics[136]. Most AURIs are caused by viral infection and usually resolved after three to seven days[137]. However, the use rate of antiviral drugs in the treatment of AURIs in children is low, and most of physicians choose newer, broad-spectrum antibiotics[42]. Therefore, identifying the characteristics of 
childhood diseases and encouraging the prescriptions of older, narrow-spectrum antibiotics rather than newer, broad-spectrum antibiotics plays an important role in the process of rational use of antibiotics. For school student, there is no systematic teaching on antibiotics, therefore, it is difficult for them to identify antibiotics. In addition, students in different regions have varieties of understandings of antibiotics. The awareness of antibiotics utilization in central urban areas is higher than that of urban and rural areas and counties in suburbs, in addition, the awareness of antibiotics utilization in high school students is higher than that in junior high school and vocational high school[121]. Therefore, more efforts should be made to improve the cognition of student in different regions and different types of school.

The high prevalence of antibiotic utilization in children might have a strong association with physicians, such as lacking of skills and knowledge, pressure from patient, physician-patient relationship, economic incentive and profit from prescribing medicine, lacking of pathogen detection or low pathogen detection rate. First, physicians in high-level hospitals are more likely to receive training on rational use of antibiotics than those in primary hospitals[138]. Physicians who has not attend related training are more likely to prescribe antibiotics[139]. However, sometimes routine training for village doctors is held regularly, however, the content of training is repeated without new course, so the training seems not effective[140]. Therefore, continuous education can narrow the knowledge gap among physicians in different levels of hospital, meanwhile, the quality of education also should be emphasized. Secondly, many caregivers faithfully embrace the effectiveness of antibiotics and injections over other regimens, and they will actively ask these therapies when visiting doctors. When physicians feel pressure from patients, about $70 \%$ of them would prescribe antibiotic[139]. On the other hand, the physician-patient relationship in China is highly strained[141]. Because there is no formal appointment system, patients generally prefer morning consultations, and there is long wait time and short consultations, which cause dissatisfaction among parents[142]. Therefore, some physicians protect themselves by regarding antibiotics as a weapon, especially expensive and injectable ones when they perceive that parents are dissatisfied[77]. They believe that prescribing antibiotics not only satisfy the patients' claims, but further ease the strained doctor-patient relationship[143]. Thirdly, economic incentive and profit from prescribing medicine also lead physicians to prescribe antibiotics. Antibiotics, which account for approximately $20 \%$ of all drug sales in general hospitals[44], are the most frequently used medicine in Chinese medical facilities. In some regions, doctors' income covered by government funds and profits from drug sales is virtually nail, these changes are not associated with improved antibiotic use. This may partly due to the low salary of medical staff, which motivates the personnel to seek additional income by providing other services and selling pharmaceutical products[144]. In addition, patient retention also could increase the income of physicians. In village clinic, if physicians adopt wait-and-watch policy or prescribe only antiviral drugs for fevers or the common cold, the caregivers would be dissatisfied with the village doctor, and would visit other village doctors. Furthermore, the primary caregivers would not return to the clinic the next time when their child had disease[120]. This may be a reason for the high prevalence of antibiotic utilization in children. Fourthly, we found that pathogen detection rate among inpatients was $44.7 \%$ in our study, which was similar to the result in another study[108]. Antibiotic use without a clear indication is common[126], it is difficult for physicians to distinguish viral infection and bacterial infection, because 
the diagnostic tests, such as a routine blood test or C-reactive test, are not available in rural settings in China, so they make decisions based on clinical experience without clear indications. However, differentiating definitively between bacterial and viral causes of respiratory infections based on signs and symptoms alone is seldomly possible, and this imprecision and concern about missed bacterial diagnosis likely drives over-prescription of antibiotics[145]. Therefore, additional tools are necessary to physicians.

Parents' perceptions and practices of how to use medicines have important effect on the management of childhood illness[146]. Through meta-analysis, we found that parents who had considerable misunderstandings may contribute to inappropriate antibiotic use. We found that $66 \%$ of caregivers believed that antibiotics could cure infection caused by viruses, a higher percentage than that was found in a pan-European study (54\%)[147]. Furthermore, half of the parents believed that antibiotics could cure common cold. Some parents often overestimate the benefits of antibiotics[148], and consider them as panacea[149]. For caregivers with correct recognition of antibiotics, the self-directed medication rate is lower than the doctor-dependent medication rate[115]. Thus, parents should receive more health education about antibiotics to improve the ability of antibiotic cognition. In addition, one study reported that about $60 \%$ of parents asked for doctors to prescribe antibiotics[150], and those who took antibiotic previously were more likely to put pressure on physicians to get them once again[151]. Other inappropriate behaviors include portraying severity of illness, or providing positive experience with use of antibiotic voluntary. However, sometimes, some physicians might misunderstand the willingness of the parents who just would like to ask for an advice or explanation from physicians rather than an antibiotic prescription[152]. Therefore, strategies for effective communication with patients and the prudent prescription of antibiotics are important. In addition, through meta-analysis, we found the overall prevalence of caregiver's self-medicating of antibiotics for children at home was $37.8 \%$, the result was lower than Yu et.al 's finding[117]. The reasons for the prevalence of self-medicating children with antibiotics are multifactorial. Storing antibiotics at home increases the probability of medicating children with antibiotics, almost $50 \%$ of the caregivers keep antibiotics at home for children[153]. Parents who keep antibiotics at home prefer to self-medicate their children rather than directly seeking advice from a medical professional[122], and people tend to use the same drugs when they confronted similar symptoms based on their experience[154]. In addition, most of home-stored antibiotics are reported to be left over from previous prescriptions[113].

Having purchased antibiotics from retail pharmacies without a physician's prescription is a critical factor contributing to self-medicating children with antibiotics. Through meta-analysis, we found that about $37 \%$ of caregivers do not know that antibiotics should only be obtained with a doctor's prescription. Although the purchase of antibiotics without a prescription is forbidden by State Food and Drug Administration regulations[155], customers nevertheless have easy access to antibiotics in most areas. Therefore, stringent implementation of regulations concerning non-prescribed antibiotics in retail pharmacies is essential to restrict access to antibiotics. 
Our study has several limitations. First, the heterogeneity across studies was statistically significant and the available data were insufficient to explain all the observed heterogeneity across studies. Second, there are few studies reported the antibiotic utilization in rural areas, however, as there is a rural population of nearly 800 million in China, antibiotic misuse in rural areas may be more serious, and we will investigate antibiotic use among children in rural areas. In addition, only published literatures were included, and potential publication bias cannot be neglected.

\section{Conclusion}

The prevalence of antibiotic utilization is much higher than the standard. The overall prevalence of antibiotic utilization among outpatients, inpatients, and caregiver's self-medicating at home were $63.8 \%$, $81.2 \%$, and $37.8 \%$ respectively. The high prevalence of antibiotics is associated with multiple factors, including at children level (e.g. distribution of disease, lacking of skills and knowledge), and physician level (e.g. lacking of skills and knowledge, pressure from patient, physician-patient relationship, economic incentive and profit from prescribing medicine, lacking of pathogen detection or low pathogen detection rate), and caregiver level (e.g. lacking of skills and knowledge, put pressure on physician to get antibiotics, behavior of self-medicating with antibiotics at home for children) and retail pharmacies level (e.g. sale antibiotics without prescription) and hospital level (e.g. ward capacity). Efforts to improve the prevalence of antibiotic utilization require multisector cooperation, and long-term efforts should target at both children and caregivers, and also prescribers, like health education or training on the proper use of antibiotics and powerful supervision. Further studies should focus on antibiotic utilization of children, especially in rural area.

\section{Abbreviations}

BRICS Brazil, Russia, India, China, and South Africa

CARSS China Antimicrobial Resistance Surveillance System

NASP National Antibiotic Stewardship Program

PRISMA Preferred Reporting Items for Systematic Reviews and Meta-Analyses

CNKI China National Knowledge Infrastructure

$\mathrm{Cl} \quad$ Confidence interval

AHRQ Agency for Healthcare Research and Quality

ARPEC Asia-Pacific Economic Cooperation

AURIs Acute upper respiratory infections 


\section{Declarations}

\section{Author Contributions}

S.G., Q.S., and X.Z. confirmed the research questions and the search strategies before screening the database. S.G. and X.Z. were the two reviewers, and they screened the titles and abstracts, read the full texts, and conducted the quality assessments for the included articles. X.Z acted as the third reviewer, made the final decision when disagreement between the two reviewers occurred. S.G. X.Z. and L.S. participated in the data extracting and checked the accuracy of the data. S.G. wrote the manuscript, and X.Z. checked the manuscript for polishing language. All authors read and approved the final manuscript.

\section{Funding}

This work was supported by National Natural Science Foundation of China (71774103) and The Fundamental Research Funds of Shandong University. The funders had no role in the study design, data collection and analysis, data interpretation, writing the manuscript, and publication.

\section{Availability of data and materials}

The datasets analyzed during the current study are not public, but are available from the corresponding author on reasonable request.

\section{Ethics approval and consent to participate}

Ethics approval for this study was not required.

\section{Consent for publication}

Not applicable.

\section{Competing interests}

The authors declare no conflicts of interest.

\section{References}

1. Wise R, Hart T, Cars 0 , et al. Antimicrobial resistance. Is a major threat to public health. BMJ. 1998;317(7159):609-10.

2. Harbarth S, Samore MH. Antimicrobial resistance determinants and future control. Emerg Infect Dis. 2005;11(6):794-801.

3. SSM N: Antibiotic resistance and the commensal flora: role of the commensal flora in the development and spread of antimicrobial resistance. Maastricht University Press; 2005.

4. Van Boeckel TP, Gandra S, Ashok A, et al. Global antibiotic consumption 2000 to 2010: an analysis of national pharmaceutical sales data. Lancet Infectious Diseases. 2014;14(8):742-50. 
5. Heddini A, Cars O, Qiang S, et al. Antibiotic resistance in China-a major future challenge. Lancet. 2009;373(9657):30.

6. Zeman K. Effectiveness and tolerance of antibiotics in pediatrics patients. Pol Merkur Lekarski. 2011;30(179):352-4.

7. Nicolini G, Sperotto F, Esposito S. Combating the rise of antibiotic resistance in children. Minerva Pediatr. 2014;66(1):31-9.

8. Pakyz AL, Gurgle HE, Ibrahim OM, et al. Trends in antibacterial use in hospitalized pediatric patients in United States academic health centers. Syst Rev. 2009;30(6):600-3.

9. Hersh AL, Shapiro DJ, Pavia AT, et al. Antibiotic prescribing in ambulatory pediatrics in the United States. Pediatrics. 2011;128(6):1053-61.

10. Levy ER, Swami S, Dubois SG, et al. Rates and appropriateness of antimicrobial prescribing at an academic children's hospital, 2007-2010. Infect Control Hosp Epidemiol. 2012;33(4):346-53.

11. Rutledge-Taylor K, Matlow A, Gravel D, et al. A point prevalence survey of health care-associated infections in Canadian pediatric inpatients. Am J Infect Control. 2012;40(6):491-6.

12. Versporten A, Bielicki J, Drapier N, et al. The Worldwide Antibiotic Resistance and Prescribing in European Children (ARPEC) point prevalence survey: developing hospital-quality indicators of antibiotic prescribing for children. J Antimicrob Chemother. 2016;71(4):1106-17.

13. Yoshida S, Takeuchi M, Kawakami K. Prescription of antibiotics to pre-school children from 2005 to 2014 in Japan: a retrospective claims database study. J Public Health (Oxf). 2018;40(2):397-403.

14. Schindler C, Krappweis J, Morgenstern I, et al. Prescriptions of systemic antibiotics for children in Germany aged between 0 and 6 years. Pharmacoepidemiol Drug Saf. 2003;12(2):113-20.

15. Zhang $W$, Shen $X$, Wang $Y$, et al. Outpatient antibiotic use and assessment of antibiotic guidelines in Chinese children's hospitals. Eur J Clin Pharmacol. 2008;64(8):821-8.

16. Nyquist AC, Gonzales R, Steiner JF, et al. Antibiotic prescribing for children with colds, upper respiratory tract infections, and bronchitis. JAMA. 1998;279(11):875-7.

17. Dong $L, Y a n H$, Wang D. Antibiotic prescribing patterns in village health clinics across 10 provinces of Western China. J Antimicrob Chemother. 2008;62(2):410-5.

18. Rogawski ET, Platts-Mills JA, Seidman JC, et al. Use of antibiotics in children younger than two years in eight countries: a prospective cohort study. Bull World Health Organ. 2017;95(1):49-61.

19. Qu M, Lv B, Zhang $X$, et al. Prevalence and antibiotic resistance of bacterial pathogens isolated from childhood diarrhea in Beijing, China (2010-2014). Gut Pathogens. 2016;8:31.

20. Li R, Xiao F, Zheng X, et al. Antibiotic misuse among children with diarrhea in China: results from a national survey. Peerj. 2016;4:e2668.

21. Surveillance of bacterial. resistance in children and newborns across China from 2014 to 2017. National Medical Journal of China. 2018;98(40):3279-87.

22. Chang $\mathrm{H}$, Shen $\mathrm{X}$, Fu Z, et al. Antibiotic resistance and molecular analysis of Streptococcus pyogenes isolated from healthy schoolchildren in China. Soc Sci Med. 2010;42(2):84-9. 
23. Yin X, Song F, Gong Y, et al. A systematic review of antibiotic utilization in China. J Antimicrob Chemother. 2013;68(11):2445-52.

24. Medernach RL, Logan LK. The Growing Threat of Antibiotic Resistance in Children. Infect Dis Clin North Am. 2018;32(1):1-17.

25. National Health Commission of the People's Republic of China. A national program for the clinical use of antibacterial agents 2011.Available from:

http://www.nhc.gov.cn/zwgkzt/wsbysj/201104/51376.shtml Accessed 9 November 20202020.

26. National Health Commission of the People's Republic of China. Administrative measures for the clinical use of antibacterial drugs 2012.Available from: http://www.gov.cn/fffg/201205/08/content_2132174.htm Accessed 9 November 20202020.

27. National Health Commission of the People's Republic of China. National action plan to combat antimcirobial resistance 2016.Available from: http://www.gov.cn/xinwen/201608/25/content_5102348.htm Accessed 9 November 20202020.

28. Moher D, Liberati A, Tetzlaff J, et al. Preferred reporting items for systematic reviews and metaanalyses: the PRISMA statement. Plos Medicine. 2009;6(7):e1000097.

29. Higgins JP, Thompson SG. Quantifying heterogeneity in a meta-analysis. Stat Med. 2002;21(11):1539-58.

30. West S, King V, Carey TS, et al. Systems to rate the strength of scientific evidence No. 47. AHRQ Publication No. 02-E016. Rockville: Agency for Health care Research and Quality; 2002.

31. Oremus $M$, Wolfson $C$, Perrault A, et al. Interrater reliability of the modified Jadad quality scale for systematic reviews of Alzheimer's disease drug trials. Dement Geriatr Cogn Disord. 2001;12(3):2326.

32. Liang X, Zhuo Y. Analysis of appliance of antibiotics about outpatient transfusion prescriptions in our hospital. Guangzhou Medical Journal. 2010;41(4):65-6.

33. Hu X. Analysis of the utilization of antibiotics in pediatric department of our hospital. China Pharmacy. 2010;21(44):4186-8.

34. Chen C, Xin L, Tan F. Analysis on the use of antibacterials in pediatric outpatient department of our hospital. China Practical Medicine. 2010;5(29):9-10.

35. Zhang J. Analysis on antibiotic treatment among pediatric outpatients in our hospital in 2010. Chinese Journal of Medicinal Guide. 2011;13(12):2166, 2172.

36. Wang J, Li G, Xiang F. Analysis of antibiotic application in outptient pediatric prescriptions. Modern Hospitals. 2011;11(5):57-8.

37. Li X. The application situation analysis of antibiotic usage in outpatient department with acute upper respiratory infections in our hospital. China Modern Medicine. 2011;18(9):150-1.

38. Liang J, Liang Y. Clinical observation of 500 cases with antibiotics in outpatient department of pediatrics. Contemporary Medicine 2012(30):144-145. 
39. Huang $X, X i e ~ J, X u Y$, et al. The investigation research of the prescription of antibiotic drugs in outpatient of the pediatric department of one hospital. Chinese Journal of Clinical Rational Drug Use. 2012;5(36):1-2.

40. Li H. Analysis and evaluation of drug application in pediatric outpatients of our hospital. China Medical Herald. 2012;9(08):114-5.

41. Chen L. Our hospital antimicrobial prescription pediatric clinic is not reasonable use analysis. Journal of North Pharmacy. 2012;9(11):66-7.

42. Zhou H, Lin Z, Lv D, et al. Investigation of the use of antibacterial drugs in pediatric outpatient department of our hospital. Chinese Journal of Pharmacovigilance. 2012;9(09):566-8.

43. Li L, Feng L. Analysis of drugs application for upper respiratory tract infection in pediatric outpatient. China Medical Herald. 2013;10(02):114-6.

44. Xiao B. Analysis of the use of antibiotics in 1553 outpatient pediatric patients. Medical Journal of National Defending Forces in Southwest China. 2013;23(07):779-80.

45. Chen H, Zhu F, Lu H. Application analysis of antibacterial drugs in pediatric outpatient department of Lianzhou People's Hospital. China Medicine Pharmacy. 2013;3(11):64-5.

46. Liu $\mathrm{H}$. The analysis of the pediatric outpatient anti-infective drug using. Hebei Medicine. 2013;19(03):436-9.

47. Miao $\mathrm{C}$, Lei $\mathrm{H}$, Rong $\mathrm{Y}$, et al: Medication analysis on pediatrics outpatient prescription at our hospital. China Health Industry 2014(4):5, 7.

48. Zeng Y. Analysis on the pediatric prescriptions in the outpatient. The Medical Forum 2014(1):121123.

49. Gui M, Wang J. To analyze the service condition of antibacterial agents of upper respiratory tract infection prescription in pediatric outpatient department. Chinese Community Doctors 2014(15):5, 7.

50. Yuan Y, Cao L, Yu X, et al. Prescriptions of antibiotics for children with upper respiratory infections in outpatient department. Chinese Journal of General Practitioners. 2015;14(8):616-20.

51. Xu P, Lin R. Investigation on current situation of using antibiotics for acute upper respiratory infection in Children. Journal of Pediatric Pharmacy. 2015;21(7):47-9.

52. Xu X, Liu T. Analysis of usage of anti-infection drugs in department of pediatrics in our hospital. China Medicine Pharmacy. 2015;5(24):72-4.

53. Gao Y. Analysis of antibiotics in pediatric patients with acute upper respiratory tract infection. Chinese Community Doctors. 2016;32(19):13-4.

54. Xie Y. MTP rationality of prescription and the effect of interventions in the treatment of acute upper respiratory tract infection in outpatient pediatrics. Anhui Medical Pharmaceutical Journal. 2016;20(9):1784-6, 1787.

55. Lin Y, Nie C, Yang L, et al. Analysis and evaluation of prescriptions for pediatric upper respiratory tract infection. China Licensed Pharmacist. 2016;13(2):15-8. 
56. Wang J. Evaluation of the use of antimicrobial drugs in pediatric outpatients with acute respiratory infection. Journal of Tropical Medicine. 2016;16(06):796-8.

57. Wang S. Analysis of antibacterials usage in respiratory tract infection of outpatient department of pediatrics in our hospital. Chinese Journal of Drug Evaluation. 2017;34(4):290-3.

58. Pan Y. Analysis on application of oral medicine for upper respiratory tract infections in our hospital. Chinese Foreign Medical Research. 2017;15(13):142-3.

59. Nie C, Zhang J, Zhao Q, et al. Investigation and analysis of antibiotics application in pediatric clinic of our hospital. Modern Hospital. 2017;17(08):1223-5.

60. Zhang Z, Hu Y, Zou G, et al. Antibiotic prescribing for upper respiratory infections among children in rural China: a cross-sectional study of outpatient prescriptions. Glob Health Action. 2017;10(1):1287334.

61. Wei X, Zhang Z, Walley JD, et al. Effect of a training and educational intervention for physicians and caregivers on antibiotic prescribing for upper respiratory tract infections in children at primary care facilities in rural China: a cluster-randomised controlled trial. Lancet Global Health. 2017;5(12):e1258-67.

62. Wei X, Yin J, Walley JD, et al. Impact of China's essential medicines scheme and zero-mark-up policy on antibiotic prescriptions in county hospitals: a mixed methods study. Tropical Med Int Health. 2017;22(9):1166-74.

63. Wang Z, Li L, Huang F, et al. Analysis of rational drug use of the pediatric prescriptions from 45 grassroots hospitals in an area. Pharmaceutical Administration. 2018;27(17):86-9.

64. Wang C. Analysis of the use of antibiotics in outpatients with acute upper respiratory tract infections in pediatrics department. Clinical Research Practice. 2019;4(03):118-9.

65. Peng L, Wang Z, Zhang Y. Analysis of rational use of antibiotic drugs in hospital pediatrics based on children's drug utilization index and drug safety. B Malariol Y Salud Amb. 2019;59(1):89-95.

66. He D. 877 example young child acute under respiratory tract infects in hospital trouble clinical analysis. Chinese Manipulation and Rehabilitation Medicine 2011(8):97.

67. Cui Y. Analysis of antibiotics in hospitalized children. Chinese Journal of Clinical Rational Drug Use. 2011;04(23):43-4.

68. Qiu Z, Xie L, Xie H. Application analysis on antibiotics in pediatric patient with acute upper respiratory tract infection. Chinese Journal of Clinical Rational Drug Use. 2011;04(25):4-5.

69. Xie H, Zhou J, Liu F. Paediatric antibiotic use and monitoring of common bacterial resistance. Chinese Journal of Ethnomedicine Ethnopharmacy. 2011;20(9):8, 10.

70. Chen J, Wen Z. Research study on antibiotic application for bronchopneumonia of the children inpatient in pediatrics in 2010. International Medicine Health Guidance News. 2011;17(24):3075-8.

71. Lin Y. Analysis of antibiotics application in pediatric upper respiratory tract infection. Chinese Journal of Nosocomiology. 2011;21(12):2576-7. 
72. Liang Z, Li L, Li K. Analysis of the use of antibiotic in pediatric inpatients. Medical Recapitulate. 2011;17(12):1890-1.

73. Zhou L. The analysis of nosocomial infection and antibiotics usage in hospitalized neonates. China Practical Medicine. 2012;07(15):32-4.

74. Bian $\mathrm{H}$, Zhang T. Investigation of drug use in pediatrics in our hospital. Chinese Journal of Pharmacoepidemiology. 2012;21(3):138-9, 145.

75. Fang J. Antibiotics application in 196 pediatric patients with acute upper respiratory infection. Journal of Modern Clinical Medicine. 2012;38(2):123-4.

76. Wu J. The Analysis of utilization of antibiotics in children with respiratory tract infection. Guide of China Medicine. 2012;10(11):31-2, 35.

77. Wu W. An empirical analysis of antibiotic drug usage in pediatrics. World Health Digest Medical Periodieal 2012(39):72-73.

78. He M. Investigation of antibiotic use in hospitalized children with respiratory tract infection in our hospital from 2009 to 2011. Gems of Health 2012(4):389.

79. Guan L. Investigation of antibiotic use in pediatric inpatient with acute upper respiratory tract infections. World Health Digest Medical Periodieal. 2012;9(49):231-2.

80. Jiang L, Yang P. Investigation and analysis of nosocomial infection and antibiotic application in 1148 hospitalized children. Journal of Frontiers of Medicine 2012(20):94-95.

81. Zhu J, Shen N, Wang Y, et al. Application of antibiotics in neonatal wards. Chinese Journal of Nosocomiology. 2012;22(17):3836-7, 3840.

82. Wang Q, Sun C, Xu Y. Analysis on the usage of antibacterials in pediatric inpatients. Chinese Journal of Drug Application Monitoring. 2012;9(06):348-50.

83. Che Y, Dong J. Use of antibiotics for neonates in a basic hospital and influencing factors analysis. Chinese Journal of Woman Child Health Research. 2013;24(3):296-8.

84. Lu J, Huang J. Clinical analysis of antibiotics application for children with acute respiratory infection in Qinzhou. Journal of Clinical Pulmonary Medicine. 2013;18(12):2210-2.

85. Xu J. Analysis of the usage of antibacterials in pediatric inpatients. Chinese Journal of Pharmacoepidemiology. 2013;22(4):196-8.

86. Huang X, Zhang W, Xu Q. Investigation of 215 medical records in internal medicine of pediatrics and analysis of antimicrobial drug Use. Journal of Pediatric Pharmacy. 2013;19(3):38-42.

87. Zhan J, Chen Q. Investigation and analysis of the application condition of antibacterial agents on hospitalization children in our hospital. Nei Mongol Journal of Traditional Chinese Medicine. 2013;32(18):96-7.

88. Li C, Ren N, Wen X, et al. Changes in antimicrobial use prevalence in China: results from five points prevalence studies. Plos One. 2013;8(12):e82785.

89. Yao Q, Luo Z. Clinical application of antibiotic in department of pediatrics. Chinese Journal of Clinical Rational Drug Use 2014(15):1-2. 
90. Wu M, Chen Y, Wu X. Investigation of pediatric medical records and analysis of antimicrobial drug application in a certain hospital. Journal of Navy Medicine 2014(4):260-262.

91. Zhu G, Wu X. Antibiotics usage analysis in pediatric inpatients. Journal of Modern Medicine Health. 2014;30(21):3239-40.

92. Liu Y. Survey and analysis of the use of antibacterials in pediatric inpatients of our hospital. China Licensed Pharmacist. 2014;11(11):13-5.

93. Huang W. Analysis of the use of antibiotic in our hospital in 2013 were from January to December in pediatrics. China Health Industry. 2014;11(21):35-6.

94. Huang G, Miao D, Lai X, et al. Investigation of use of antibiotics by hospitalized neonates. Chinese Journal of Nosocomiology. 2014;24(01):97-8.

95. Cheng $X$, Yan $X$, Lin S. The Investigation and analysis of antimicrobial drugs used by 258 pediatric inpatients. Journal of Hubei University for Nationalities Medical Edition. 2014;31(02):40-1.

96. Cheng H, Wu D. Survey of antimicrobial agents use in pediatric inpatients. Chinese Journal of Pharmaco Epidemiology. 2014;23(12):737-40.

97. Chen Y, Ye J. Pharmaceutical intervention on the use of antibiotics in the neonatology of X-hospital. China Health Industry 2015(16):12-14.

98. Li L, Xu H, Zhou J, et al. Application effect of clinical pathway management in infantile capillary bronchitis and the impact on antibiotics utilization ratio. Chinese Journal of Clinical Rational Drug Use. 2017;10(12):35-6, 41.

99. Su X, Zhu H, Yuan H. Analysis of antibiotic use for bronchial pneumonia in pediatrics. Journal of Kunming Medical University. 2017;38(7):126-9.

100. Zhu J, Luo M, Li L, et al. Promotion of PDCA cycle on rational usage of antibiotics in neonatal department. Journal of Guangdong Pharmaceutical University. 2017;33(5):649-53.

101. Li R, Zhang J, Li G. Analysis of clinical antibiotic use and adverse reactions in pediatrics. Chinese Nursing Research. 2018;32(23):3815-7.

102. Chen $Z$, Xiao Y. Analysis on usage of antibacterial drugs in inpatient children of Tianjin Children's Hosptial in 2016. Drugs Clinic. 2018;33(03):672-5.

103. Zhang JS, Liu G, Zhang WS, et al. Antibiotic usage in Chinese children: a point prevalence survey. World Journal of Pediatrics. 2018;14(4):335-43.

104. Ju J. Study on the effect of pharmacist intervention on rational use of pediatric antibiotics. China Foreign Medical Treatment. 2019;38(7):127-9.

105. Wei W, Wang XF, Liu JP, et al. Status of antibiotic use in hospitalized children with communityacquired pneumonia in multiple regions of China. Chinese journal of contemporary pediatrics. 2019;21(1):11-7.

106. Niu J. Analysis on the treatment and intervention of pediatric upper respiratory tract infection in hospital. Chinese Community Doctors. 2020;36(16):18. 
107. Miao R, Wan C, Wang Z, et al. Inappropriate antibiotic prescriptions among pediatric inpatients in different type hospitals. Medicine. 2020;99(2):e18714.

108. Zhang $M, M a X Y$, Feng ZQ, et al. Survey of antibiotic use among hospitalised children in a hospital in Northeast China over a 4-year period. Journal for Specialists in Pediatric Nursing. 2020;25(2):e12282.

109. Wei X, Zhang Z, Hicks JP, et al. Long-term outcomes of an educational intervention to reduce antibiotic prescribing for childhood upper respiratory tract infections in rural China: Follow-up of a cluster-randomised controlled trial. Plos Medicine. 2019;16(2):e1002733.

110. Cui $F$, Yuan $Y$, Cui $H$, et al: A survey on the knowledge of antibiotics of children parents in three children-hospitals of Beijing. Chinese Journal of Medicine 2015(8):67-70.

111. Zhao M, Nan W, Jiao X, et al. Survey on the parent situation of antibacteriol drugs use for children. Northwest Pharmaceutical Journal. 2016;31(02):200-2.

112. Yin Y, Cui N. Antibiotics use among preschool children and parental cognition in Ji'nan city. Chinese Journal of Public Health. 2018;34(1):118-20.

113. Peng D, Zhou X. Parents' antibiotic use for children in Ningbo: knowledge, behaviors and influencing factors. Journal of Zhejiang University. 2018;47(2):156-62.

114. Yao Z, Zhou J, Li Y, et al. Prevalence of self-medication with antibiotics in kindergarten children of Guangzhou city. Chinese Journal of Public Health. 2013;29(10):1485-7.

115. Miao R. Investigation on the impact of parents' cognitive level of antibiotics on self-directed use of antibiotics in pupils. Practical Preventive Medicine. 2013;20(1):42-5.

116. Zhang G, Cao L, Yuan Y. 10 years' changes on parent's antibiotic knowledge in Beijing. Chinese Journal of Medicine 2014(10):41-44.

117. Yu M, Zhao G, Stålsby LC, et al. Knowledge, attitudes, and practices of parents in rural China on the use of antibiotics in children: a cross-sectional study. Bmc Infectious Diseases. 2014;14:112.

118. Ding L, Sun W, Li Y, et al. Studying on the status of rural parents' cognition on antibiotics and its influencing factors. Chinese Health Service Management. 2016;33(2):111-4.

119. Cen Q, Dai D. The relationship between novice mother and neonates in use of antibiotic cold medications and the effects of health education. Drug Evaluation. 2016;13(21):47-50.

120. Zhang Z, Zhan X, Zhou H, et al. Antibiotic prescribing of village doctors for children under 15 years with upper respiratory tract infections in rural China: A qualitative study. Medicine. 2016;95(23):e3803.

121. Cheng YC, Pan YP, Zhang Y, et al. Investigation of the cognition and behavior on drug safety in Beijing middle school students. Journal of Peking University (Health Sciences). 2017;49(6):1038-43.

122. Chang J, Lv B, Zhu S, et al. Non-prescription use of antibiotics among children in urban China: a cross-sectional survey of knowledge, attitudes, and practices. Expert Rev Anti Infect Ther. 2018;16(2):163-72. 
123. Fan W, Mu J, Song X, et al. Investigation on antibiotic cognition and use of parents of preschool children in Tianjin. Chinese Primary Health Care. 2019;33(4):61-2.

124. Ge Y, Chipenda DS, Liao XP. Advanced neonatal medicine in China: Is newborn ward capacity associated with inpatient antibiotic usage? Plos One. 2019;14(8):e219630.

125. Cheng J, Chai J, Sun Y, et al. Antibiotics use for upper respiratory tract infections among children in rural Anhui: children's presentations, caregivers' management, and implications for public health policy. J Public Health Policy. 2019;40(2):236-52.

126. Wang J, Sheng Y, Ni J, et al. Shanghai parents' perception and attitude towards the use of antibiotics on children: A cross-sectional study. Infection Drug Resistance. 2019;12:3259-67.

127. Ye $\mathrm{D}$, Yan $\mathrm{K}$, Zhang $\mathrm{H}$, et al. A survey of knowledge, attitudes and practices concerning antibiotic prescription for upper respiratory tract infections among pediatricians in 2018 in Shaanxi Province, China. Expert Rev Anti Infect Ther. 2020;18(9):927-36.

128. Wei X, Deng $S$, Haldane V, et al. Understanding factors influencing antibiotic prescribing behaviour in rural China: a qualitative process evaluation of a cluster randomized controlled trial. J Health Serv Res Policy. 2020;25(2):94-103.

129. Zhang J, Cameron D, Quak SH, et al. Rates and determinants of antibiotics and probiotics prescription to children in Asia-Pacific countries. Beneficial Microbes. 2020;11(4):329-38.

130. Wang J, Huang C, Li Z, et al. Knowledge and behavior of antibiotic use for upper respiratory tract infection among parents of young children in Changsha city. Chinese Journal of Public Health. 2017;33(3):415-8.

131. Zhang Y, Lin S, Li G, et al. Cognition and usage of antibiotics in caregivers of $0-6$ years old children in the rural area of Weinan City, 2015. Practical Preventive Medicine. 2017;24(2):196-8.

132. Li W, Lu Y, Chen M, et al. Meta-analysis on Antibiotics Usage in Children with Upper Respiratory Tract Infection in China. Chinese Pharmaceutical Journal. 2017;52(10):880-5.

133. Department of Health $\mathrm{MoH}$. National antimicrobial drug clinical application special rehabilitation program (Excerpt). Chinese Community Physician (Medical) 2012, 14(8).

134. Poole NM, Shapiro DJ, Fleming-Dutra KE, et al: Antibiotic prescribing for children in United States emergency departments: 2009-2014. Pediatrics 2019, 143(2).

135. Kumar R, Goyal A, Padhy BM, et al. Self-medication practice and factors influencing it among medical and paramedical students in India: A two-period comparative cross-sectional study. J Nat Sci Biol Med. 2016;7(2):143-8.

136. Zhao H, Bian J, Han X, et al: Outpatient antibiotic use associated with acute upper respiratory infections in China: a nationwide cross-sectional study. Int J Antimicrob Agents 2020:106193.

137. Hao Q, Dong BR, Wu T. Probiotics for preventing acute upper respiratory tract infections. Cochrane Database Syst Rev 2015(2):D6895.

138. Bai Y, Wang S, Yin X, et al. Factors associated with doctors' knowledge on antibiotic use in China. Sci Rep. 2016;6:23429. 
139. Sun Q, Dyar OJ, Zhao L, et al. Overuse of antibiotics for the common cold - attitudes and behaviors among doctors in rural areas of Shandong Province, China. BMC Pharmacol Toxicol. 2015;16:6.

140. Yin J, Dyar OJ, Yang P, et al. Pattern of antibiotic prescribing and factors associated with it in eight village clinics in rural Shandong Province, China: a descriptive study. Trans R Soc Trop Med Hyg. 2019;113(11):714-21.

141. Ma S, Huang Y, Yang Y, et al. Prevalence of burnout and career satisfaction among oncologists in China: A national survey. Oncologist. 2019;24(7):e480-9.

142. Yin J, Wei X, Li H, et al. Assessing the impact of general practitioner team service on perceived quality of care among patients with non-communicable diseases in China: a natural experimental study. Int J Qual Health Care. 2016;28(5):554-60.

143. Kunin CM, Tupasi T, Craig WA. Use of antibiotics. A brief exposition of the problem and some tentative solutions. Ann Intern Med. 1973;79(4):555-60.

144. Wang J, Wang $P$, Wang $X$, et al. Use and prescription of antibiotics in primary health care settings in China. Jama Internal Medicine. 2014;174(12):1914-20.

145. McKay R, Mah A, Law MR, et al. Systematic review of factors associated with antibiotic prescribing for respiratory tract infections. Antimicrob Agents Chemother. 2016;60(7):4106-18.

146. Togoobaatar G, Ikeda N, Ali M, et al. Survey of non-prescribed use of antibiotics for children in an urban community in Mongolia. Bull World Health Organ. 2010;88(12):930-6.

147. Grigoryan L, Burgerhof JG, Degener JE, et al. Attitudes, beliefs and knowledge concerning antibiotic use and self-medication: a comparative European study. Pharmacoepidemiol Drug Saf. 2007;16(11):1234-43.

148. Coxeter PD, Mar CD, Hoffmann TC. Parents' expectations and experiences of antibiotics for acute respiratory infections in primary care. Annals of Family Medicine. 2017;15(2):149-54.

149. Sun X, Jackson S, Carmichael GA, et al. Prescribing behaviour of village doctors under China's New Cooperative Medical Scheme. Soc Sci Med. 2009;68(10):1775-9.

150. Zeru T, Berihu H, Buruh G, et al. Parental knowledge and practice on antibiotic use for upper respiratory tract infections in children, in Aksum town health institutions, Northern Ethiopia: a crosssectional study. Pan Afr Med J. 2020;35:142.

151. El-Hawy RM, Ashmawy MI, Kamal MM, et al. Studying the knowledge, attitude and practice of antibiotic misuse among Alexandria population. European Journal of Hospital Pharmacy-Science Practice. 2017;24(6):349-54.

152. Connelly J. Critical realism and health promotion: effective practice needs an effective theory. Health Educ Res. 2001;16(2):115-9.

153. Sun C, Hu YJ, Wang $X$, et al. Influence of leftover antibiotics on self-medication with antibiotics for children: a cross-sectional study from three Chinese provinces. Bmj Open. 2019;9(12):e33679.

154. Jin C, Ely A, Fang L, et al. Framing a global health risk from the bottom-up: User perceptions and practices around antibiotics in four villages in China. Health Risk Society. 2011;13(5):433-49. 
155. China Food and Drug Administration. Provisions for supervision of drug distribution 2007.Available from: http://eng.sfda.gov.cn/WS03/CL0768/61650.html. Accessed 29 November 20202020.

Figures

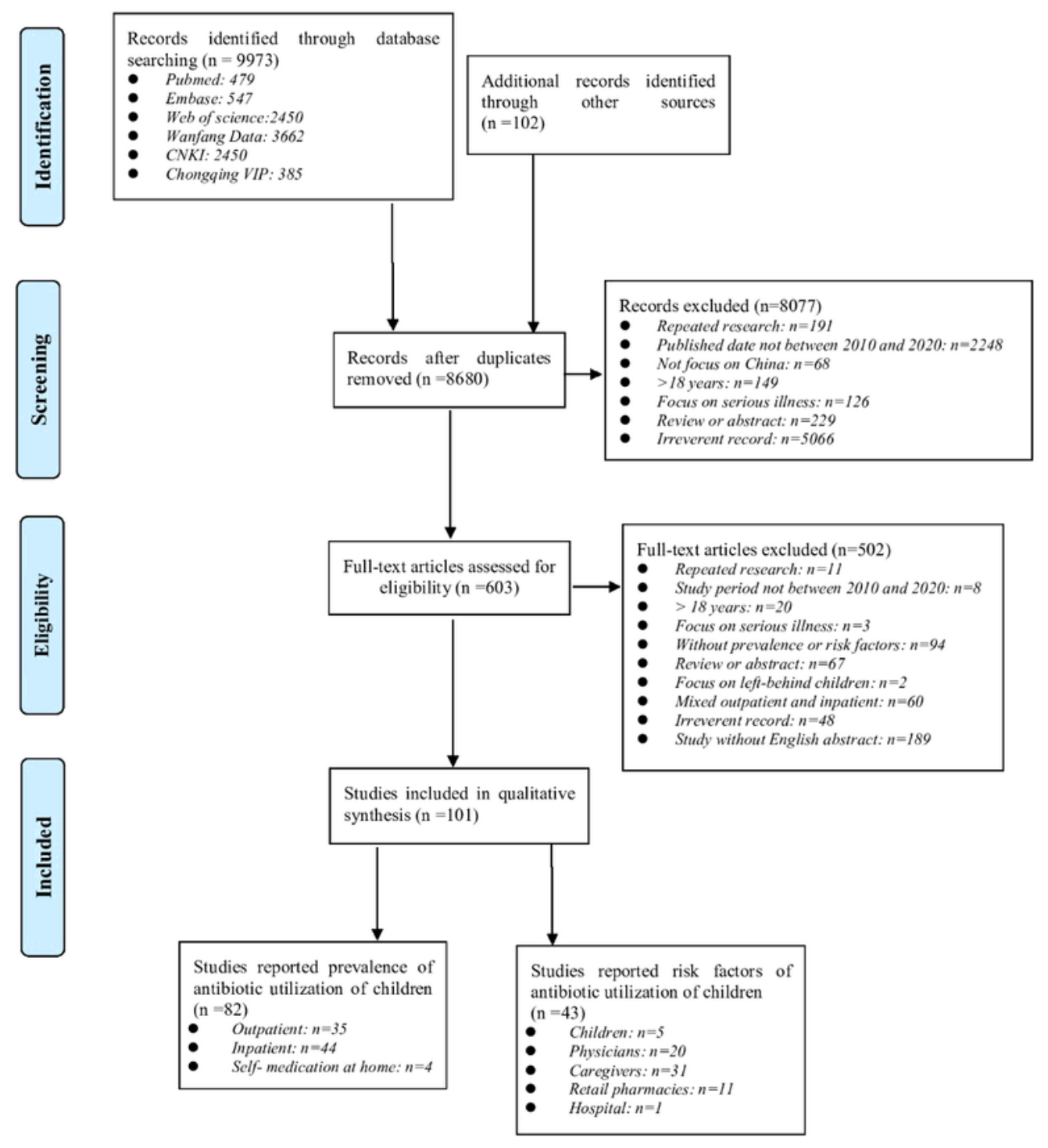

Figure 1 
PRISMA flowchart of study selection process. PRISMA: Preferred Reporting Items for Systematic Reviews and Meta-Analyses CNKI: China National Knowledge Infrastructure

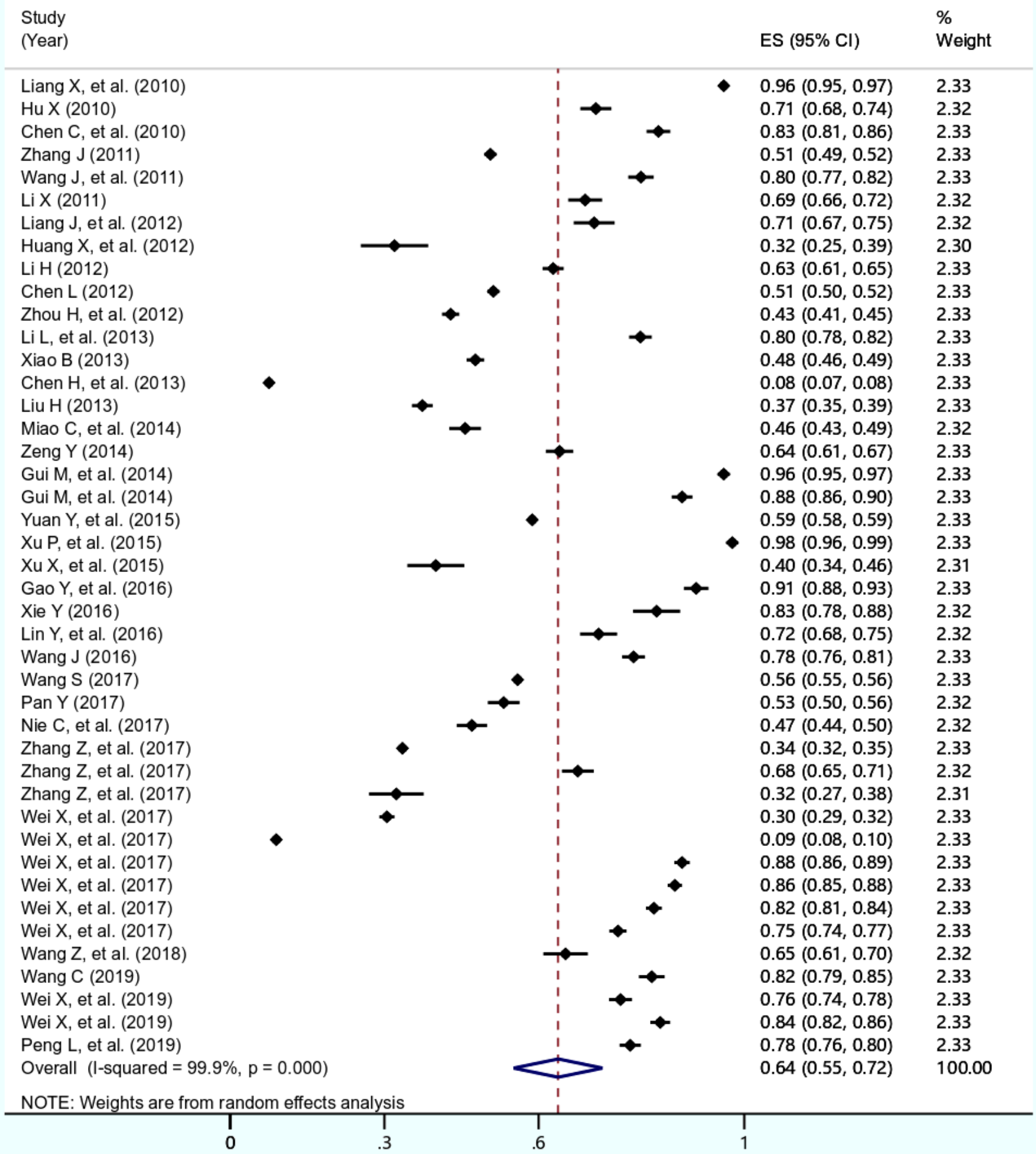

\section{Figure 2}

Forest plot of the studies for prevalence of antibiotic utilization of outpatient. 


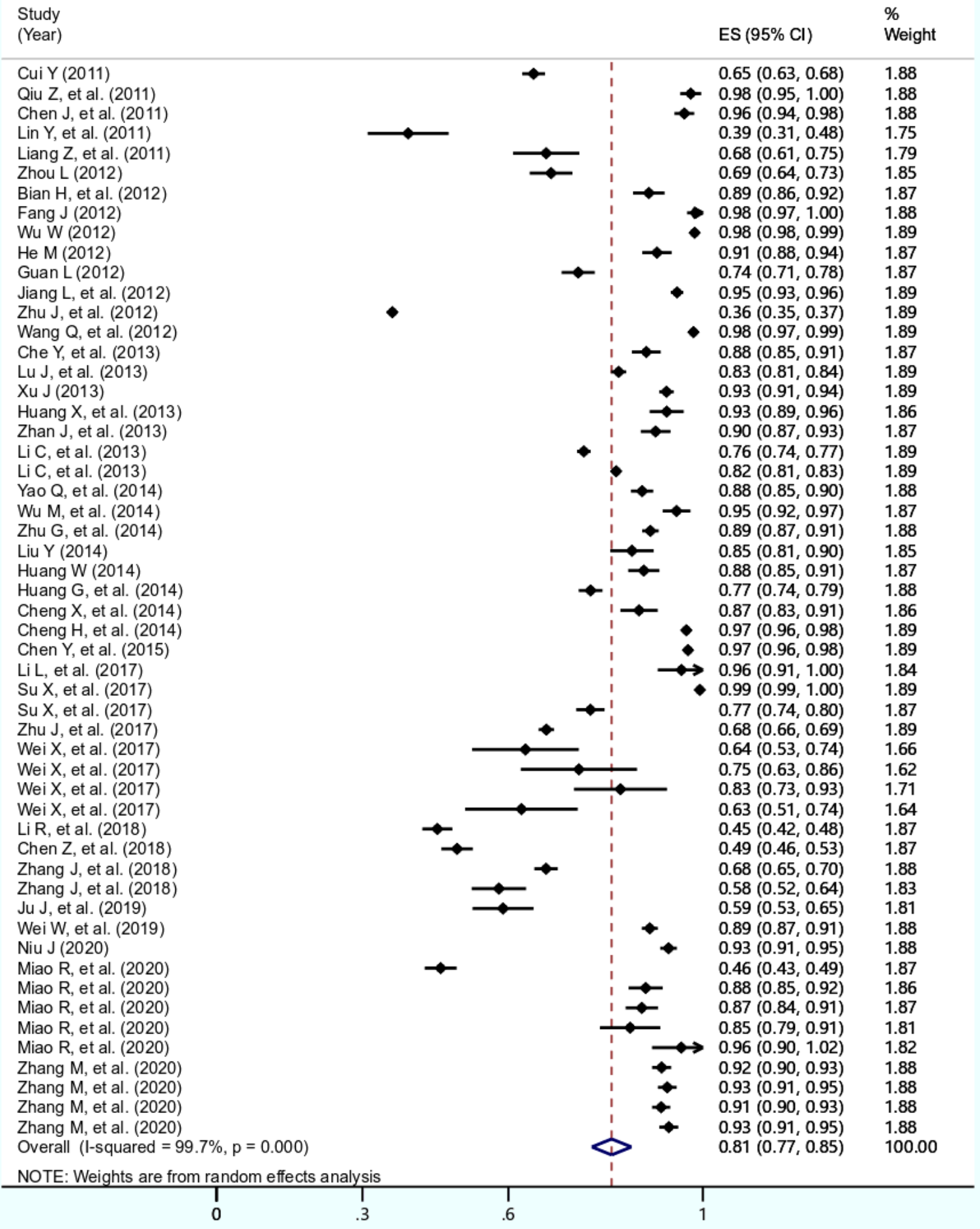

\section{Figure 3}

Forest plot of the studies for prevalence of antibiotic utilization of inpatient. 


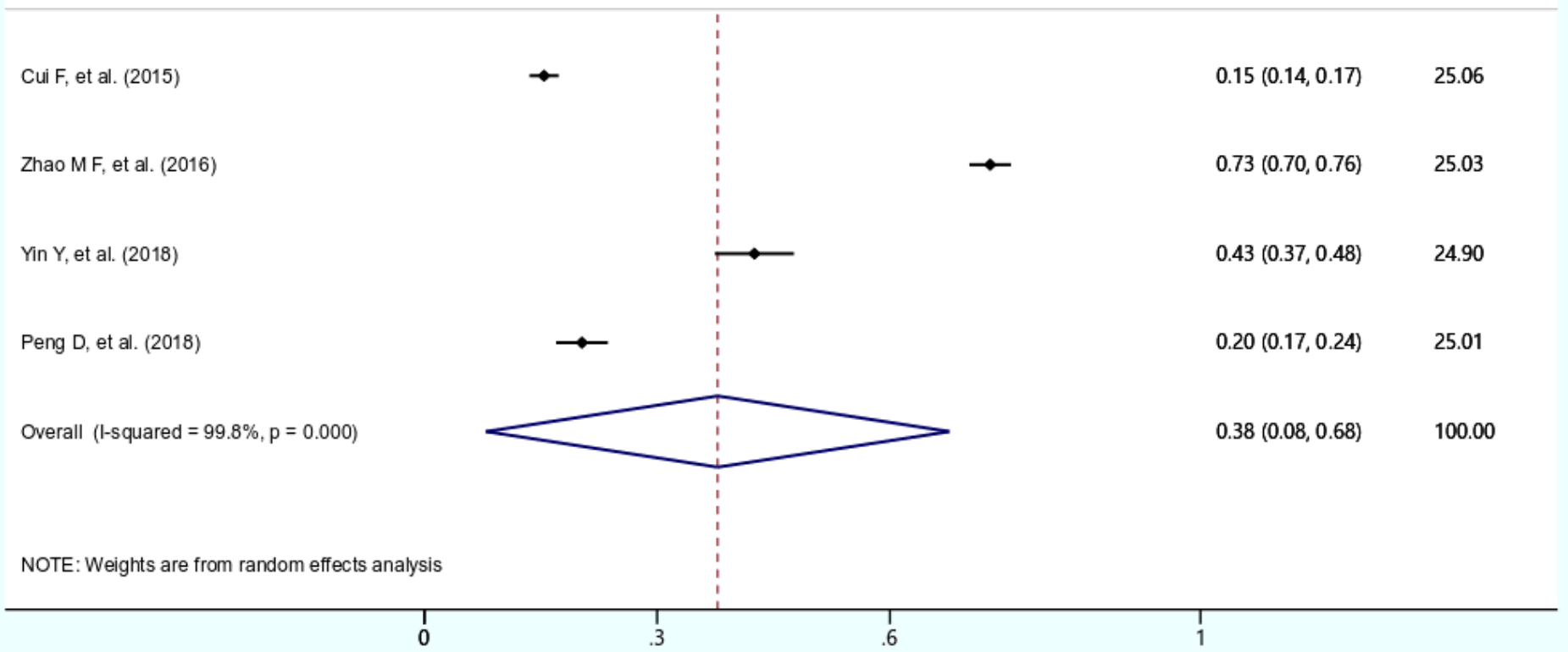

\section{Figure 4}

Forest plot of the studies for prevalence of self-medicating at home.

\section{Supplementary Files}

This is a list of supplementary files associated with this preprint. Click to download.

- Appendix.docx 